\title{
Perception of students about community medicine course in Hawler College of Medicine, Iraq
}

\section{Abubakir M. Saleh *}

\section{Abstract}

Background and objective: Community medicine is an important discipline for medical students who are going to be future doctors and deal with different health problems. Community Medicine is taught in $3^{\text {rd }}, 4^{\text {th }}$ and $6^{\text {th }}$ year of study at Hawler College of Medicine. The aim of the study was to explore students' perception about this subject because it plays an important role in determining educational outcome.

Methods: This study was carried out in Hawler College of Medicine, Erbil city, Iraqi Kurdistan Region in the academic year 2013-2014. It was based on a self-administered questionnaire survey of $4^{\text {th }}$ year students. The questionnaire consisted of closed and open ended questions related to the attitude of students toward community medicine course, views on the positive and negative aspects and recommendations to improve the course. The quantitative data were analysed through using the statistical package for the social sciences (version 19), while qualitative data analysis comprised thematic analysis of open-ended questions using common coding techniques.

Results: The result of this study suggested that high percentage of the students had positive attitude toward the course. Sixty-six respondents $(55.4 \%)$ mentioned that there are positive aspects in the course like research project $(33.3 .1 \%)$, having respectful and friendly teachers $(31.8 \%)$ and participation of students in discussions in the classroom. Sixty-six respondents (55.4\%) mentioned that there are negative aspects in the course like short duration of the course $(27.2 \%)$ and some topics were repeated from other years. Fifty-seven respondents $(47.8 \%)$ have recommended a number of priorities for improving the quality of the course like: increasing practical sessions with more student participation (36.8\%); decreasing theoretical lectures $(22.8 \%)$ and the time for the research should be isolated without lectures (19.2\%).

Conclusion: Community medicine course is well perceived by the students with some negative aspects. Some recommendations have been made for improving the quality of the course.

Keywords: Community Medicine, Hawler College of Medicine, student perception, Erbil.

\section{Introduction}

Community medicine is an important discipline for medical students who are going to be future doctors and deals with different health problems. It is important that medical students understand the community medicine principles and are able to apply these principles in their future life as a doctor. Although only small number of graduates from different medical colleges around the world will eventually choose community medicine as their specialty but the current shift in health care from curative to preventive medicine makes community-based medical education of utmost importance. ${ }^{1-3}$ Despite this shift, the importance of community medicine is still not fully appreciated with more focus on clinical and hospital based rather than preventive and community based education. ${ }^{1,4}$ For health professionals to be able to fully understand the findings of different researches, and to make correct decisions, they need to be

* Department of community medicine, college of medicine, Hawler Medical University, Erbil, Iraq. 
equipped with knowledge of community medicine and to be able to critically review literatures and identify problems in the design, analysis and interpretation of the results. ${ }^{5,6}$ The community medicine module exists in the curriculum of most of the medical colleges throughout the world but with great variation regarding duration and contents. For instance in the majority of medical schools in the USA, the module includes biostatistics, epidemiology, preventive medicine, demography, and medical informatics, which are taught during the first or second study year. ${ }^{7}$ In Ziauddin University in Pakistan, the module includes epidemiology, biostatistics, and survey methodology courses that are taught in the first two years of medical school. ${ }^{8}$ In South Africa, biostatistics and research methodology are taught in the year 1 and 2 with further reinforcement practiced in year 3 and 4 in some universities. $^{9}$ In 44 medical schools in Turkey, biostatistics is usually taught in the $1^{\text {st }}$ year. ${ }^{10}$ Outcome based medical education, which is now implemented by many medical schools, could be viewed as the modern model of medical education that focuses on measuring student performance of different skills and practical procedures rather than on the resources available to the student. ${ }^{11,12}$ Several studies in the field have emphasized the decisive role that students' perceptions and attitudes about a subject play in the achievement of educational outcomes. ${ }^{13-14}$ Perception is defined as the process of attaining awareness or understanding of sensory information, which an individual exhibits towards certain processes, situations, objects or persons. ${ }^{15}$ While medical curriculum must be effective and relevant, but how effective and relevant they are may be a matter of perception. Many authors agree that multiple assessment of any curriculum should be done through perception of students which eventually lead to improvement and more effective curriculum. ${ }^{1}$ Community medicine is taught in the $3^{\text {rd }}, 4^{\text {th }}$ and $6^{\text {th }}$ year of study at
Hawler College of Medicine. In $4^{\text {th }}$ year of study, it is usually taught as a course of eight weeks duration which contains different topics like epidemiology, biostatistics, occupational and environmental health and health care administration. The aim of this study was to explore students' perception about this subject because it plays an important role in determining educational outcome.

\section{Methods}

Setting and time: This study was carried out in Hawler College of Medicine, Erbil city, Iraqi Kurdistan Region in the academic year 2013- 2014. Hawler College of Medicine was established in 1977 as part of University of Suleymania in Suleymania governorate, and then moved to Erbil governorate in 1982 as one of the University of Salahaddin's colleges till 2005. Then Hawler Medical University was established in Erbil and College of Medicine became one of its main institutions. The college is governed by the college council headed by the dean. ${ }^{16}$

Design: This study was based on a selfadministered questionnaire survey of $4^{\text {th }}$ year students.

Participants: All fourth year students in the college of medicine in the academic year 2013-2014.

Data collection: A questionnaire designed by the researcher based on two resources; review of literature related to perception of students about different medical undergraduate courses and informal interview with students in the college. The questionnaire was developed in English language, which is the instructional language in the university. The questionnaire comprised of three sections. The first section comprised of demographic characteristics of the participants like age and gender. The second section comprised of thirty questions related to the attitude of the participants toward the course of community medicine like attitude toward the course in general, attitude toward lecturers, assessment of the students, attitude toward teachers, and attitude 
toward knowledge and skills gained from the course. Answers were to be provided on five point Likert scales ranging from one (strongly disagree) to five (strongly agree). The third section addressed the participants' view on the positive aspects of the course, negative aspects of the course in addition to the recommendations for improving the quality of the course.

Data analysis: The quantitative data were analysed using the statistical package for the social sciences (version 19). Responses to opinion statements were clustered into three groups: "strongly agree and agree", "undecided" and "disagree and strongly disagree". The qualitative data analysis comprised thematic analysis of open-ended questions using common coding techniques through reading the answers on the questions and identifying main themes within the answers. Using these identified themes, a structured classification of codes was generated. The data were coded in a series of steps, and the code structure was revised and refined multiple times as new insights were developed and new relationships between the themes present in the answers were elicited. Finally the themes were revised and refined ensuring that they reflect the answers received from the respondents. Each open item was analyzed and reported independently. More than one response was coded for each subject when necessary. Duplicate answers were only coded once.

Ethical consideration: The study was approved by the Research Ethics Committee of the College of Medicine. Informed consent was obtained from all the participants in the study.

\section{Results}

Of the 148 fourth year students invited to participate in the survey, 119 completed the questionnaire giving a response rate of $80.4 \%$. The mean age $( \pm S D)$ of the respondents was $21.4 \pm 0.81$ years. Sixtyfive respondents $(54.6 \%)$ were females, while $54(45.4 \%)$ were males. The male: female ratio was 1.2:1.

Perception of students about elements of the course : Most of the students had positive attitude toward the course value like understanding the main concept of community medicine (40.3\%), improving problem solving skills $(36.1 \%)$, gaining skills to design research $(40.3 \%)$, and the gained knowledge and experiences that is useful to their career as a doctor (42.0\%). Whereas, some students showed a negative attitude toward some elements of the course like the lectures were not interesting and stimulating (44.6\%), lectures were lengthy $(40.3 \%)$, too many lectures for one day $(32.7 \%)$ and the assessment process focuses mainly on the theory rather than practice and daily activities of the students (Table 1 ).

Table 1: Perception of students about elements of the course

\begin{tabular}{|c|c|c|c|c|c|c|}
\hline Statements & \multicolumn{2}{|c|}{$\begin{array}{l}\text { Strongly agree } \\
\text { and agree } \\
\text { No. (\%) }\end{array}$} & \multicolumn{2}{|c|}{ Undecided } & \multicolumn{2}{|c|}{$\begin{array}{l}\text { Strongly disagree } \\
\text { and disagree }\end{array}$} \\
\hline I understood the main concept of community medicine & 48 & $(40.3)$ & 47 & $(39.4)$ & 24 & $(20.1)$ \\
\hline I realized the relevance of community medicine to the real health issue & 43 & $(36.1)$ & 55 & $(46.2)$ & 21 & $(17.7)$ \\
\hline My skills improved in solving problems & 43 & $(36.1)$ & 46 & $(38.7)$ & 30 & $(25.2)$ \\
\hline I gained skills to design research & 48 & $(40.3)$ & 51 & $(42.9)$ & 20 & $(16.8)$ \\
\hline The gained knowledge and experiences is useful for my career as a doctor & 50 & $(42.0)$ & 45 & $(37.8)$ & 24 & $(20.1)$ \\
\hline Sequencing of topics in the course was logical. & 40 & $(33.6)$ & 57 & $(47.8)$ & 22 & $(18.5)$ \\
\hline The lectures were interesting and stimulating & 24 & $(20.1)$ & 42 & $(53.3)$ & 53 & $(44.6)$ \\
\hline The lectures were lengthy & 48 & $(40.3)$ & 45 & $(37.8)$ & 26 & $(21.8)$ \\
\hline Too many lectures for one day & 38 & $(32.7)$ & 40 & $(33.6)$ & 41 & $(34.4)$ \\
\hline Teachers encourage students for participation in classroom discussion & 63 & $(52.9)$ & 42 & $(35.2)$ & 14 & $(11.7)$ \\
\hline There were no specific references & 31 & $(26.6)$ & 48 & $(40.3)$ & 40 & $(33.7)$ \\
\hline It focuses on the health problems of Kurdistan region and Iraq & 48 & $(40.4)$ & 33 & $(27.7)$ & 38 & $(31.9)$ \\
\hline It focuses on the practical sessions rather than didactic lectures. & 24 & $(20.2)$ & 35 & $(29.4)$ & 60 & $(50.4)$ \\
\hline $\begin{array}{l}\text { The assessment focuses on theory rather than on practical examination } \\
\text { and daily activities of the students in the class. }\end{array}$ & 42 & $(35.3)$ & 51 & $(42.9)$ & 26 & $(21.8)$ \\
\hline
\end{tabular}


http://dx.doi.org/10.15218/zjms.2015.0036

Positive aspects of the curriculum: Sixty -six of one hundred nineteen respondents $(55.4 \%)$ mentioned that there are positive aspects in the course like research project (33.3.1\%), having respectful and friendly teachers $(318 \%)$, participation of students in discussion in the classroom (13.6\%) and practical sessions $(13.6 \%)$ as shown in Table 2.

Negative aspects of the course: Sixty-six of one hundred nineteen respondents $(55.4 \%)$ mentioned that there are negative aspects in the course like short duration of the course and unorganized schedule $(27.2 \%)$, some topics were repeated from other years, meaningless and boring $(21.2 \%)$, research project took most of our time and we were unable to study other subjects $(15.1 \%)$ and some teachers copy their presentation from internet with too many text and they are just reading them without any explanation (10.6 \%) as shown in Table 3.

Table 2: Positive aspects identified by the students $(n=66)$.

\begin{tabular}{llc}
\hline \multirow{2}{*}{ Positive aspects ( $\mathbf{n = 6 6 )}$} & \multicolumn{2}{c}{ Response* $^{*}$} \\
\hline Research project & 22 & 33.3 \\
Teacher were respectful , dealing with students friendly and encouraging & 21 & 31.8 \\
them for participation, & & \\
Participation of students in the discussion in the classroom & 9 & 13.6 \\
Comfortable and relaxed course & 9 & 13.6 \\
Practical sessions & 9 & 13.6 \\
Understanding important health problems in our community & 7 & 10.6 \\
Subjects were appropriate and interested & 6 & 9.0 \\
Duration and schedule of the course & 4 & 6.0 \\
Understanding important role of community medicine & 3 & 4.5 \\
Small number of students in the hall & 2 & 3.0 \\
\hline
\end{tabular}

* Multiple responses are considered

Table 3: Negative aspects identified by the students.

\begin{tabular}{lll}
\hline Negative aspects (n=66) & No. & \% \\
\hline Short duration of the course and unorganized schedule & 18 & 27.2 \\
Some topics were repeated from other years, meaningless and boring. & 14 & 21.2 \\
Research project took most of our time and we were unable to study other subjects. & 10 & 15.1 \\
Some teachers copy their presentation from internet with too many text and they are & 7 & 10.6 \\
just reading them without any explanation. & & \\
Large number of lectures & 5 & 7.5 \\
Assessment methods with unfair distribution of marks & 3 & 4.5 \\
Absence of practical sessions in health centres & 3 & 4.5 \\
Some of teaching staff are not well trained with poor attitude, scientific background & 3 & 4.5 \\
and language in addition to inappropriate behaviour & & \\
Focus more on the theory & 3 & 4.5 \\
Introduced in wrong year of study & 3 & 4.5 \\
Two teaches in one session & 3 & 4.5 \\
Poor assistant of students in term of research project & 3 & 4.5 \\
Attendance registration policy & 2 & 3.0 \\
\hline${ }^{*}$ Multiple responses are considered & & \\
\hline
\end{tabular}


Suggestions for improvement of the course Fifty-seven respondents $(47.8 \%)$ have recommended a number of priorities for improving the quality of the course like increasing practical sessions with more student participation (36.8\%), decreasing theoretical lectures $(22.8 \%)$, the time for the research should be isolated without lectures $(19.2 \%)$, every teacher should make his own presentation which contain only the headlines $(14.0 \%)$ and increasing duration of the course with putting few days off at the end of the course (10.5\%). Details of the recommendations for improving the course as identified by the respondents are shown in Table 4.

\section{Discussion}

The result of this study suggested that high percentage of the students had positive attitude toward the course. The positive attitude of the students may be due to the content of the course which is highly organized and taught by specialised medical doctors in the field of community medicine who could relate the topics of the course to the real health issues of the region. A similar finding was reported from a Pakistani medical institute, where the majority of students surveyed showed a positive response regarding the relevance of biostatistics and epidemiology to medical curriculum. ${ }^{8}$ A researcher from Croatia also reported positive attitudes about science and scientific research in medicine among undergraduates. ${ }^{17}$ It was previously reported that biostatistics is one of the subjects in the medical curriculum that is potentially disliked by the majority of undergraduate students, most likely because it encompasses mathematics and calculation which can cause confusion. ${ }^{18-20}$ The finding that students found lectures lengthy, not interested and not stimulating them to study may be attributed to the teaching activities used, prior exposure of the student to biostatistics and epidemiology, and the experience of the lecturer. Instructors have diverse background and varying talents in terms of teaching skills, degree of emphasis and approach of teaching. Each has his or her own style, strength, weakness, and vision of how the instructions should be introduced. Shift of interest to clinical studies may be explained by the fact medical students do

Table 4: Priorities for improving the course as identified by the students.

\begin{tabular}{|c|c|c|}
\hline \multirow{2}{*}{ Priority areas $(n=57)$} & \multicolumn{2}{|c|}{ Response $^{*}$} \\
\hline & No. & $(\%)$ \\
\hline Increasing practical sessions with more student participation & 21 & 36.8 \\
\hline Decreasing theoretical lectures. & 13 & 22.8 \\
\hline $\begin{array}{l}\text { The time for doing research should be isolated and increased without any } \\
\text { theoretical lectures. }\end{array}$ & 11 & 19.2 \\
\hline $\begin{array}{l}\text { Every teacher should make his own presentation which contains only the } \\
\text { headline so that he can explain the subject rather than just reading them. }\end{array}$ & 8 & 14.0 \\
\hline $\begin{array}{l}\text { Increasing the duration of the course with putting few days off at the end } \\
\text { of the course }\end{array}$ & 6 & 10.5 \\
\hline Some topics including the research project should be taken in third year & 5 & 8.7 \\
\hline Focusing more on health problems of our community. & 5 & 8.7 \\
\hline Removing attendance registration & 4 & 7.0 \\
\hline Removing the course completely & 4 & 7.0 \\
\hline $\begin{array}{l}\text { Changing the assessment methods with increasing mark of the research } \\
\text { project. }\end{array}$ & 2 & 3.5 \\
\hline
\end{tabular}


not envision a career as investigator; they tend to concentrate on more traditional medicine subjects. This shift is also attributed to the fact that statististics is a different subject from those on which the students spend most of their time. ${ }^{21}$ The negative attitude toward assessment methods may be due to that most of the assessments methods are summative in nature and usually done at the end of the course, so the students have to study more to memorize all these theoretical information throughout the course. Among the perceived difficulties by students, which may affect the outcome of the course, is the lack of practicing exercise for the topic. This was attributed to the short duration of the course which included many activities per day. A finding that was consistent in a high proportion of students regarding the perceived difficulties and possible solutions was the recommendation to give more time for the course, designate a small group session following each lecture, and to introduce practical sessions of data collection and analysis. An American study had shown that students' early participation in research activity improve their knowledge and attitude towards research. ${ }^{22}$

\section{Conclusion}

The community medicine course is well perceived by the students. Many positive aspects were identified like research project, well trained and respectful teachers, participation of students in discussions in the classroom. Some negative aspects were also identified by the students like short duration of the course and repetition of some topics. Students have recommended a number of priorities for improving the quality of the course like increasing practical sessions with more student participation, the time allocated for conducting research project should be adequate and the need for increasing the duration of the course.

\section{Conflicts of interest}

The author reports no conflicts of interest.

\section{References}

1. Navinan MR, Wijayaratne DR, Rajapakse S. Final year students' perception regarding the curriculum in public health. Indian $\mathrm{J}$ community Med 2011; 36(4):268-74.

2. Dare AJ, Bullen C. Shifting perceptions and challenging the profession's paradigms: Reflection from undergraduate week of population health. N Z Med J 2008; 121:45-50.

3. Hensel WA, Smith DD, Barry DR, Foreman R. Changes in medical education: the community perspective. Acad Med 1996; 71:441-6.

4. Gordon L. Public health is more important than health care. J Public Health Policy 1993; 14: 261-4.

5. Appleton DDR. What statistics should we teach medical undergraduates and graduates? Statistics in Medicine 1990; 9(9):1013-21.

6. Looney SW, Grady CS, Steiner RP. An update on biostatistics requirements in US medical schools. Acad Med 1998; 73(1):92-4.

7. Daher AM, Amin F. Assessing the perceptions of a biostatics and epidemiology module: View of Year 2 medical students from a Malaysian university. A cross-sectional survey. BMC Med Educ 2010; 10:34.

8. Ahmad F, Zehra N, Omair A, Anjum Q. Students' opinion regarding application of epidemiology, biostatistics and survey methodology courses in medical research. J Pak Med Assoc 2009; 59 (5):307-10.

9. Dommisse J, Joubert G. Profile of research methodology and statistics training of undergraduate medical students at South African universities. SA Fam Pract 2009; 51(2):158-61.

10. Ercan I, Ozkaya G, Ocakoglu G, Yazici B, Sezer A, Ediz B. Determining Biostatistics Knowledge of Students and Physicians in Medical School. Inter Stat 2008; 3:1-17.

11. Harden RM. Developments in outcome-based education. Med Teach 2002; 24(2):117-20.

12. Harden RM, Crosby JR, Davis MH. An introduction to outcome-based education. Med Teach 1999; 21(1):7-14.

13. Hoat LN, Son NM, Wright EP. Perceptions of graduating students from eight medical schools in Vietnam on acquisition of key skills identified by teachers. BMC Med Educ 2008; 8(1):5.

14. Victor MN, Maria MM, Elsa CM. Perceptions on the importance of gerontological education by teachers and students of undergraduate health sciences. BMC Med Educ 2007; 7(1).

15. Lempp $H$, Seale C. The hidden curriculum in undergraduate medical education: qualitative study of medical students' perceptions of teaching. BMJ 2004; 329(7469):770-3.

16. Hawler College of Medicine: Self study report. Erbil: College of Medicine, Hawler Medical University. Unpublished report, 2011. 
17. Darko H, Ivan K, Imir L, Ana M, Ivana V, Ana V, et al. Teaching research methodology in medical schools: students' attitudes towards and knowledge about science. Med Educ 2004; 38(1):81-6.

18. Sahai $H$. Teaching biostatistics to medical students and professionals: Problems and solutions. International Journal of Mathematical Education in Science and Technology 1999; 30 (2):187-96.

19. Mostert P. Changing approaches and perceptions: biostatistics and its role in teaching the Stellenbosch doctor. In Proceedings of the Seventh International Conference on the Teaching of Statistics (ICOTS 7): 2006; Salvador, Brazil. Aukland: IASE; 2006.

20. Lam YM. Teaching statistics to medical students in the New Medical School. Journal of the Hong Kong Medical Association 1986; 38(4):196-8.

21. Altman DG, Bland JM. Improving doctors' understanding of statistics. Journal of the Royal Statistical Society Series A (Statistics in Society) 1991; 154(2)223-67.

22. Segal S, Lloyd T, Houts PS, Stillman PL, Jungas RL, Greer RB. The association between students' research involvement in medical school and their postgraduate medical activities. Acad Med 1990; 65(8):530-3. 